\title{
Racismo y daguerrotipos. Retratos de personas de origen africano y asiático para Louis Agassiz, 1850
}

\author{
Cristina Masferrer León \\ Instituto Nacional de Antropología e Historia \\ cristina_masferrer@inah.gob.mx \\ Artículo bajo licencia Creative Commons \\ Atribución 4.0 Internacional (CC BY 4.0) \\ ENVIADO: 2019-03-29 \\ ACEPTADO: 2019-06-04
}

\section{RESUMEN}

El objetivo de este artículo es analizar el vínculo entre el racismo y los daguerrotipos de personas afrodescendientes y chinas que fueron obtenidos a petición de Louis Agassiz, quien nutrió esta doctrina con sus teorías sobre la diversidad humana. La investigación se guía por dos miradas contrastantes. La primera busca aproximarnos a la manera que Agassiz observaba las imágenes que Joseph Zealy y Lorenzo Chase hicieron para él en 1850, mientras que la segunda, responde a un posicionamiento como historiadores y antropólogos, para descubrir aspectos centrales sobre las personas de origen africano y asiático que aparecen en estos daguerrotipos.

PALABRAS CLAVES

Racismo, Daguerrotipos, Afrodescendientes, Chinos, Mujeres.

\section{RESUMO}

O objetivo deste artigo é analisar o vínculo entre o racismo e os daguerreotipes de pessoas afrodescendentes e de chinesas que foram obtidos sob pedido de Louis Agassiz, que nutriu essa doutrina com suas teorias sobre a diversidade humana. A pesquisa é guiada por dois olhares contrastantes. 0 primeiro, busca nos aproximar da maneira em que Agassiz observava as imagens que Joseph Zealy e Lorenzo Chase fizeram para ele em 1850, enquanto o segundo responde a um posicionamento como historiadores e antropólogos, para descobrir aspectos centrais sobre as pessoas de origem africana e asiática que aparecem nesses daguerreotipes.

\section{PALAVRAS-CHAVE}

Racismo, Daguerrotipos, Afrodescendientes, Chinos, Mujeres.

\section{ABSTRACT}

This paper analyzes the relation between racism and the daguerreotypes of African descendant and Chinese people which were taken for Louis Agassiz, who helped developing this doctrine with his theories on human diversity. The research focuses on two contrasting views. First, it approaches to the way Agassiz might have understood the images that Joseph Zealy and Lorenzo Chase made for him in 1850 . The second one is a historical and anthropological perspective, to discover the main aspects of the African and Asian descendant people that appear in these daguerreotypes.

\section{KEYWORDS}

Racism, Daguerrotypes, African Descendants, Chinese, Women. 


\section{INTRODUCCIÓN}

Este artículo analiza el vínculo entre el racismo y los daguerrotipos que fueron obtenidos para el reconocido científico Louis Agassiz en 1850. Busco plantear nuevas preguntas a fotografías que han sido estudiadas por otros investigadores e integrar al análisis daguerrotipos de personas "chinas" que han recibido menos atención (cfr. Wallis, 1995; Murray 2012-2013; Rogers, 2012; Machado 2012). Para lograrlo, se parte de dos preguntas que esperan dar cuenta de perspectivas contrastantes: 1) ¿Cuál era la mirada de Louis Agassiz sobre estas imágenes?; 2) Como historiadores y antropólogos, ¿qué podemos decir sobre las personas de origen africano y asiático que observamos en ellas?

Peter Burke (2005:158) advertía que la mirada, ya fuera occidental, científica, colonial, turística o masculina, "a menudo expresa una actitud mental de la que el espectador puede o no ser consciente, tanto si sobre el otro se proyecta miedos, como temores o deseos". Parto de la propuesta de este historiador para lograr una historia cultural y una antropología histórica de las imágenes que reconstruya "las normas o convenciones, conscientes o inconscientes, que rigen la percepción y la interpretación de las imágenes en el seno de una determinada cultura” (p. 229). Las imágenes están lejos de ser un cristal transparente hacia el pasado o un espejo de la realidad, no obstante, "el testimonio acerca del pasado que ofrecen las imágenes es realmente valioso, complementando y corroborando el de los documentos escritos” (p. 235).

La primera mirada que busco escudriñar es la que pudo haber tenido Louis Agassiz acerca de estos daguerrotipos, sobre todo a partir del poligenismo, teoría que colaboraba a desarrollar en ese momento. Para lograrlo, se analizan las imágenes a la luz de sus propios escritos y de las obras que su esposa, Elizabeth Cary Agassiz, escribió y editó, destacando la influencia que otros científicos tuvieron en el desarrollo de sus investigaciones. Asimismo, se parte de estudios acerca de este personaje, reconocido por colaborar en el desarrollo del racismo pseudocientífico norteamericano en el siglo XIX, cuyas trágicas consecuencias se consideran un crimen contra la humanidad (Lurie, 1954; Gould, 2011).

La segunda mirada se centra en las personas que aparecen en los daguerrotipos, con especial atención a dos de las mujeres que fueron fotografiadas, orientando la reflexión a conocer aspectos sobre ellas en tanto sujetos sociales e históricos. Estos daguerrotipos muestran a mujeres y hombres de diferentes edades, que fueron actores sociales e históricos. Los antropólogos Mintz y Price (2012:122) afirman que un hecho incuestionable al estudiar las sociedades y culturas de origen africano en América es "la humanidad de los oprimidos y la inhumanidad de los sistemas que los oprimieron". Por tanto, reconocer que se trató de seres humanos con agencia -a pesar de la condición de esclavitud en que algunos de ellos vivieron-, obliga a plantearnos preguntas sobre su origen, familia y vida cotidiana. La segunda mirada es, pues, la de una etnohistoriadora y antropóloga preocupada por reconocer la agencia y el papel histórico de estas personas.

El texto inicia con una descripción de las fuentes históricas en las que se centra la investigación. Posteriormente, se analiza la mirada que Louis Agassiz pudo haber tenido sobre los daguerrotipos que Lorenzo Chase y Joseph Thomas Zealy realizaron para él en 1850 , considerando las teorías que desarrollaba sobre el origen de las "razas" humanas. Finalmente, presento una reinterpretación de estas fuentes encaminada a conocer algunos aspectos básicos de las personas que se observan en las imágenes. $\mathrm{El}$ trabajo considera veintiún daguerrotipos, pero me centro en aquellos donde aparecen Lum-Akum y Drana, mujeres de origen asiático y africano, respectivamente. 


\section{LAS FUENTES HISTÓRICAS: VEINTIÚN DAGUERROTIPOS DE 1850}

Los originales de los daguerrotipos que se analizan se resguardan en el Museo Peabody de Arqueología y Etnología de la Universidad de Harvard. La mayoría de ellos se encuentran disponibles para su consulta en línea y descarga en el sitio: pmem. unix.fas.harvard.edu:8080/peabody (cinco fueron examinados a partir de las reproducciones de Wallis, 1995:46-47).

Los daguerrotipos fueron obtenidos en 1850 por los fotógrafos Zealy y Chase, y se asume que fueron propiedad de Agassiz (ya sea porque explícitamente se indica que son parte de su colección o por la semejanza con las imágenes de sus colecciones; algunas incluso muestran a la misma persona, pero en diferente posición). En el archivo se encuentran quince daguerrotipos tomados por Zealy que muestran a cinco hombres y dos mujeres de origen africano que residían en Carolina del Sur (EUA). Por su parte, se resguardan once daguerrotipos de Lorenzo Chase, donde aparecen dos hombres "nativo-americanos", dos hombres "hindúes", dos hombres "chinos", dos mujeres adultas "chinas" y una "niña” "china”; de Massachusetts, Boston.

Se consultaron estos veintiséis daguerrotipos, pero me centro en aquellos que muestran a personas de origen africano y asiático o "chino", los cuales suman veintiuno. Dada la importancia de analizar series de imágenes (Burke, 2005:239), los daguerrotipos se consideran en su conjunto, aunque se analizan con especial énfasis los que muestran a Lum-Akum y Drana. Se han excluido los daguerrotipos de "hindúes" porque Agassiz consideraba que ellos eran parte de la "raza Caucásica", la cual ocupaba el lugar más alto en la jerarquía racial que proponía. Las siguientes tablas resumen información básica de estos daguerrotipos.

\begin{tabular}{|c|c|c|c|}
\hline & Nombre & Origen & Información adicional \\
\hline 1 & $\begin{array}{l}\text { Aleet-Mong (aka } \\
\text { "T'sow-Chaoong") }\end{array}$ & Chino & $\begin{array}{l}\text { Hombre con trenza, sombrero } \\
\text { y vestimenta china. De frente, } \\
\text { hasta la cintura. }\end{array}$ \\
\hline 2 & $\begin{array}{l}\text { Aleet-Mong (aka } \\
\text { "T'sow-Chaoong") }\end{array}$ & Chino & $\begin{array}{l}\text { Hombre con trenza, sombrero } \\
\text { y vestimenta china. Rostro de } \\
\text { perfil, cuerpo en tres cuartos, } \\
\text { hasta la cintura. }\end{array}$ \\
\hline 3 & $\begin{array}{l}\text { Soo-Chune } \\
\text { (aka “Le-Kaw-Hing") }\end{array}$ & Chino & $\begin{array}{l}\text { Hombre con trenza, sombrero } \\
\text { y vestimenta china. De perfil, } \\
\text { hasta la cintura. }\end{array}$ \\
\hline 4 & Pwan Ye-Koo & Chino & $\begin{array}{l}\text { Mujer de perfil, hasta la } \\
\text { cintura, con peinado elaborado, } \\
\text { aretes y vestimenta china. }\end{array}$ \\
\hline 5 & Pwan Ye-Koo & Chino & $\begin{array}{l}\text { "Niña" de frente, hasta la } \\
\text { cintura, con vestimenta china. }\end{array}$ \\
\hline 6 & Lum-Akum & Chino & Mujer de perfil, hasta la cintura. \\
\hline
\end{tabular}

$1 \quad$ Fuente: Elaboración propia con información de: Museo Peabody de Arqueología y Etnología, Universidad de Harvard, pmem.unix.fas.harvard. edu:8080/peabody. Lugar: Suffolk, Massachusetts, Boston, EUA. Dimensiones: $2.75 \times 2.25$ pulgadas.

\begin{tabular}{|c|c|c|c|}
\hline & Nombre & Origen & Información adicional \\
\hline 1 & Renty & Congo & $\begin{array}{l}\text { Hombre de perfil, desnudo hasta la cintura. } \\
\text { Un papel dice: "Renty, Congo, B.F. Taylor, } \\
\text { Esq. Columbia, S.C." }\end{array}$ \\
\hline 2 & Renty & Congo & $\begin{array}{l}\text { Hombre de frente, desnudo hasta la } \\
\text { cintura. Un papel dice: "Renty, Congo, on } \\
\text { plantation of B.F. Taylor, Columbia, S.C." }\end{array}$ \\
\hline 3 & Jem & - & $\begin{array}{l}\text { Hombre de perfil, cuerpo entero, desnudo. } \\
\text { De pie sobre una alfombra con patrones. } \\
\text { Un papel dice “Jem". }\end{array}$ \\
\hline 4 & Jem & - & $\begin{array}{l}\text { Hombre de frente, cuerpo entero, desnudo. } \\
\text { De pie sobre una alfombra con patrones. } \\
\text { Un papel dice “Jem". }\end{array}$ \\
\hline 5 & Jem & Gullah & $\begin{array}{l}\text { Hombre, vista trasera, cuerpo entero, } \\
\text { desnudo. De pie sobre una alfombra con } \\
\text { patrones. Un papel dice ""Jem, Gullah", } \\
\text { belonging to F.W.Green, Columbia, S.C.". }\end{array}$ \\
\hline 6 & Jack & Guinea & $\begin{array}{l}\text { Hombre, de perfil, desnudo hasta la } \\
\text { cintura. Un papel dice “Jack (driver), } \\
\text { Guinea. Plantation of B. F. Taylor, Esq. } \\
\text { Columbia, S.C.” }\end{array}$ \\
\hline & Jack & Guinea & $\begin{array}{l}\text { Hombre, de frente, desnudo hasta la } \\
\text { cintura. Un papel dice “Jack (driver), } \\
\text { Guinea. Plantation of B. F. Taylor, Esq. } \\
\text { Columbia, S.C." }\end{array}$ \\
\hline & Fassena & Mandingo & $\begin{array}{l}\text { Hombre, de perfil, desnudo hasta la } \\
\text { cintura. Se indica que dos líneas paralelas } \\
\text { van de la mejilla a la sien. Un papel dice } \\
\text { "Fassena (carpenter) Mandingo, plantation } \\
\text { of Col. Wade Hampton, near Columbia, } \\
\text { South Carolina" }\end{array}$ \\
\hline & Fassena & Mandingo & $\begin{array}{l}\text { Hombre, de frente, desnudo hasta la } \\
\text { cintura. La ropa se abulta en la cintura. Un } \\
\text { papel dice "Fassena (carpenter) Mandingo, } \\
\text { plantation of Col. Wade Hampton, near } \\
\text { Columbia, South Carolina” }\end{array}$ \\
\hline & Drana & $\begin{array}{l}\text { Nacida } \\
\text { en EUA } \\
\text { "Country } \\
\text { born" }\end{array}$ & $\begin{array}{l}\text { Mujer madura, desnuda hasta la cintura, } \\
\text { de perfil. Ropa acumulada /abultada en } \\
\text { la cintura. Un papel dice: “Drana. country } \\
\text { born, daughter of Jack, Guinea. Plantation } \\
\text { of B.F. Taylor Esq. Columbia S.C.” }\end{array}$ \\
\hline & Drana & $\begin{array}{l}\text { Nacida } \\
\text { en EUA } \\
\text { "Country } \\
\text { born" }\end{array}$ & $\begin{array}{l}\text { Mujer madura, desnuda hasta la cintura, de } \\
\text { frente. Ropa acumulada en la cintura. Un } \\
\text { papel dice: "Drana. country born, daughter } \\
\text { of Jack, Guinea. Plantation of B.F. Taylor } \\
\text { Esq. Columbia S.C." }\end{array}$ \\
\hline & Delia & $\begin{array}{l}\text { Nacida } \\
\text { en EUA } \\
\text { "Country } \\
\text { born" }\end{array}$ & $\begin{array}{l}\text { Mujer joven, desnuda hasta la cintura, de } \\
\text { perfil. Se indica que la ropa está abultada } \\
\text { en la cintura como si se hubiera removido } \\
\text { para la fotografía. Un papel dice: “Delia, } \\
\text { country born of African parents, daughter of } \\
\text { Renty, Congo". }\end{array}$ \\
\hline & Delia & $\begin{array}{l}\text { Nacida } \\
\text { en EUA } \\
\text { "Country } \\
\text { born" }\end{array}$ & $\begin{array}{l}\text { Mujer joven, desnuda hasta la cintura, } \\
\text { de frente. Un papel dice: "Delia, country } \\
\text { born of African parents, daughter of Renty, } \\
\text { Congo". }\end{array}$ \\
\hline & Alfred & Fula & $\begin{array}{l}\text { Hombre desnudo, cuerpo entero, de perfil. } \\
\text { Un papel dice: "Alfred, Foulah, belonging to } \\
\text { I. Lomas, Columbia, S.C." }\end{array}$ \\
\hline & Alfred & Fula & $\begin{array}{l}\text { Hombre maduro, desnudo, cuerpo entero, } \\
\text { vista trasera. Un papel dice: "Alfred, Foulah } \\
\text { Columbia, S.C.” }\end{array}$ \\
\hline
\end{tabular}

Tabla 2. Daguerrotipos de personas de origen africano ("negros"), Joseph Zealy, $1850 .^{2}$

$2 \quad$ Fuente: Elaboración propia con información de: Museo Peabody de Arqueología y Etnología en la Universidad de Harvard, pmem.unix.fas.harvard. edu:8080/peabody. Lugar: Richland, Columbia, Carolina del Sur, EUA. Dimensiones: $4.68 \times 3.81$ pulgadas. 
En cuanto a la materialidad del archivo, las fotografías se encontraban montadas en un estuche de metal con marcos dorados alrededor de los retratos que asemejan ventanas que determinan la mirada del espectador. Del lado opuesto, se observa una tela roja, posiblemente colocada para evitar que se dañen las imágenes al cerrar los estuches y para decorarlos. En el caso de los daguerrotipos de Chase, los marcos dorados llevan una inscripción que indica su nombre y alrededor de éste, un marco rojo. Estos permiten apreciar las fotografías a través de formas circulares, rectangulares u octagonales. En cambio, los estuches de las fotografías de Zealy tienen una inscripción sobre la tela roja y sus marcos dorados muestran las imágenes a partir de una forma irregular que asemeja ser un octágono compuesto por curvas.

Lorenzo Chase fue reconocido como artista dedicado a los daguerrotipos en la segunda mitad del siglo XIX; además, se cree que fue masón. Aunque por un tiempo vivió en San Francisco, residió mayormente en Boston (Peter y Kailbourn, 2000:174). La galería de Joseph Zealy fue descrita en un periódico local en 1891 -cuarenta años después de tomar los daguerrotipos para Agassiz-. En dicha nota el estudio se consideró de "buen gusto" y se explicó que el cuarto donde tomaba las fotografías se encontraba "bien amueblado", con un piano elegante para las damas visitantes; seguido de este estudio había otra habitación para el "arreglo personal" de sus visitas; todo se encontraba "magníficamente iluminado" con numerosas ventanas y un tragaluz construido para su "arte”, asegurando "el más perfecto terminado" de sus imágenes (Wallis, 1995:60). Todos estos aspectos son condiciones de construcción visual controlada que determinan el trabajo de registro dentro del estudio.

\section{LOUIS AGASSIZ. LA MIRADA RACISTA}

Hacia mediados del siglo XIX, tanto en Estados Unidos como en Europa se discutía si los seres humanos eran parte de una misma especie (monogenismo) o si, por el contrario, las poblaciones humanas -que en ese entonces se consideraban incuestionablemente como razas-, tenían un origen múltiple (poligenismo). Louis Agassiz (1807-1873) nació en Suiza y se había especializado en el estudio de los peces, pero su destino terminaría en Estados Unidos, del lado de los poligenistas. Migró a Boston en 1846 y posteriormente fundó y dirigió el Museo de Zoología Comparada de la Universidad de Harvard (Gould, 2011:86-87). Fue un naturalista sumamente reconocido que consolidó la biología norteamericana aunque eventualmente se opuso tenazmente a las teorías de Darwin (Gould, 2011:87; Irmscher, 2013).

De acuerdo a Jay Gould, Agassiz originalmente apoyaba las teorías de un origen humano común. En una carta que este naturalista escribió a su madre en 1846, Louis Agassiz relató lo siguiente:

Fue en Filadefia donde estuve por primera vez en contacto prolongado con los negros; todos los criados de mi hotel eran hombres de color. Apenas puedo expresarte la penosa [dolorosa] impresión que me produjeron, sobre todo porque lo que sentí es contario a nuestras ideas acerca de la confraternidad del tipo [género] humano y el origen único de nuestra especie. Pero lo único que cuenta es la verdad. Sin embargo, sentí piedad al contemplar a esta raza degradada y degenerada, y me llené de compasión al pensar en su destino, si es que son realmente hombres. Sin embargo, no puedo evitar la impresión [es imposible para mi reprimir el sentimiento] de que no tienen [no son de] la misma sangre que nosotros (Agassiz en Gould, 2011:90).

A pesar de la aparente honestidad de Agassiz, resulta difícil creer que ideas semejantes no rondaran su mente desde antes del fatídico encuentro que describe en la comunicación epistolar con su progenitora. Georges Cuvier (1769-1832) fue su "amado maestro" (Agassiz, 1885:168) ; el mismo que en 1816 disecó el cuerpo de la recién fallecida Sara "Saartjie" Baartman (17891815) y mutiló sus restos para guardar su cerebro y genitales en frascos (South African History Onilne, 2013). Cuando estaba viva, la exhibieron en circos y estudiaron su cuerpo; tras el análisis de sus restos mortales, Cuvier determinó que ella y los hottentotes o khoikhoi -grupo étnico del sur de África- representaban un punto intermedio entre los seres humanos y otros animales: "Nunca he visto una cabeza humana más parecida a la de un mono que la de esta mujer" (Cuvier citado en Gould, 2011:145).

Agassiz (1885:417) también era admirador de Samuel G. Morton y su colección de más de seiscientos cráneos humanos. Lo consideró "el pilar de la Academia de Filadelfia" y lo describió como un "hombre de ciencia en el mejor sentido; admirable por su conocimiento y su actividad" (Carta de Agassiz a Milne Edwards, 1847, en Agassiz, 1885: 438). Morton publicó libros y ensayos que tuvieron una significativa influencia en las propuestas del naturalista suizo, quien no dudaba en citar dichas obras para fundamentar sus propias interpretaciones. En 1839, Morton publicó su célebre obra Crania Americana, acompañada del texto: "Un ensayo sobre las variedades de las especies humanas" (Morton, 1839). En 1844, presentó su libro Crania Aegyptiaca, y el ensayo: "Una investigación sobre las características distintivas de la raza aborigen de América" (Morton, 1844a 
y 1844 b). Además, tan solo un año antes de que Louis Agassiz publicara sus propias consideraciones sobre el origen de las razas humanas, se imprimió el escrito de Morton, titulado "Observaciones sobre el tamaño del cerebro de varias razas y familias del hombre" (Morton, 1849).

El ensayo "The diversity of origin of the human races", de la autoría de Agassiz, apareció en el periódico Christian Examiner en julio de 1850 -a escasos meses de que se obtuvieran los daguerrotipos que se analizan en este artículo-, aunque la publicación se basó en una conferencia que dictó en marzo del mismo año, ante la Asociación Americana para el Avance de la Ciencia (Wallis, 1995). En este texto, Agassiz (1850: 2) afirmaba la unidad de la humanidad pero se preguntaba sobre la diversidad del origen de las razas humanas, considerándola una pregunta sin nexo religioso, sino sólo vinculado a los intereses de la Historia Natural. Reconoció la relación de estas indagaciones con el apoyo a la esclavitud, pero se defendió diciendo que él únicamente se haría cargo de la pregunta sobre el origen del hombre, dejando que los políticos hicieran lo que pudiesen con los resultados. Así, procuró desvincularse explícitamente de cualquier lazo con asuntos políticos, en particular con la condición política de los “negroes" (Agassiz, 1885:4,30). Por supuesto, cabe preguntarnos si el uso de la palabra negroes, -en lugar de otros términos que él mismo empleó en otros momentos, como negros [black], etíopes o africanos-, revela cómo el contexto político estaba inmerso en el discurso que él pretendía que fuera científico. Años después, en 1863, Agassiz mantuvo comunicación con Samuel G. Howe, quien apoyaba la abolición de la esclavitud a pesar de mostrarse preocupado por lo que ocurriría con la "raza blanca" y la "raza negra" si ello se lograba (carta de Louis Agassiz a Howe, 1863, en Agassiz, 1885:591617). Louis Agassiz le explicó que los mulatos eran "híbridos desafortunados" producto de una "amalgama antinatural"; creía que en los estados del sur continuaría la persistencia de la raza negra, aunque esperaba que gradualmente "desaparecieran" ["die out"] del norte; estaba convencido de que todos "merecían su libertad" y debían "ser iguales ante la ley" aunque advertía que "ningún hombre tiene derecho a lo que no es capaz de usar"; no pensaba "justo" ni "seguro" garantizar a los negros todos los "privilegios" que los blancos habían logrado mediante "largas luchas" (p. 607-609). Por tanto, propuso "tener cuidado de garantizar demasiado a la raza negra desde el principio", para no tener que privarles después de ciertos privilegios que pudieran usar en detrimento suyo y de los blancos (p. 608).

A pesar de afirmar que todos los seres humanos eran parte de una misma especie, en su artículo de 1850, Agassiz cuestionó el origen común de la humanidad empleando los datos que -como experto naturalista decimonónico- tenía disponibles sobre otras especies, como peces, medusas, abejas, aves, gatos, caballos, leones y lobos. También recurrió a la información que conocía sobre ciertas civilizaciones para afirmar que había "razas históricas" y "razas no-históricas" (en términos del Génesis bíblico), las cuales pensaba que se habían mantenido desconectadas unas de otras (Agassiz, 1850: 3,15). Afirmó que no había habido "nunca" una "sociedad regulada de hombres negros" (p. 35). A partir de argumentos relacionados con estos dos ámbitos del saber, Agassiz propuso que la distribución geográfica de los animales en general $-y$ de los humanos en particular- mostraban evidencia de un plan llevado a cabo de manera independiente a la variación climática: un plan diseñado por un "inteligente Creador” (p. 14).
Este tipo de argumentos sin duda recibieron influencia de los escritos de Morton, quien poco antes había afirmado que su perspectiva no era incompatible con las Sagradas Escrituras; y que las evidencias históricas sobre monumentos egipcios comprobaban que las razas ya eran distintas desde 3500 años atrás, sugiriendo que las razas que él identificaba eran coetáneas con la dispersión primitiva de la especie humana (Morton, 1844b:36). Desde 1839 Morton había propuesto un mapa con la ubicación de las razas humanas y sin duda fue considerado por Agassiz para imaginar la distribución geográfica de éstas.

Morton (1839:5-7) consideraba la existencia de 22 familias humanas, que se podían agrupar en cinco "razas": Caucásica, Mongólica, Malaya, Americana y Etíope. Afirmaba que la Caucásica tenía la facilidad de las dotes intelectuales más superiores; quienes pertenecían a la Mongólica eran ingeniosos, imitativos y muy susceptibles de ser civilizados; los Malayos eran activos e ingeniosos, estaban habituados a la migración y a las actividades marítimas; los americanos tenían una aversión a la cultura, eran lentos para adquirir conocimientos, vengativos y amantes de la guerra; finalmente, aquellos de la raza Etíope -a quienes simplemente llamaba negros- eran considerados celosos, flexibles e indolentes, con una diversidad en cuanto a su carácter intelectual, pero Morton afirmaba que dentro de ella se encontraba el extremo más bajo en términos intelectuales, “con el grado más bajo de la humanidad" (p. 5-7).

Louis Agassiz (1850) señaló la existencia de cinco "tipos" humanos, que sin duda alguna nos recuerdan la propuesta de Morton: Caucásicos, Mongoles, Malayos, Indios americanos y Africanos. Para él, no tenía importancia si estos tipos eran llamados "razas", "variedades" o "especies" de la familia humana mientras quedara claro que presentaban una diversidad peculiar desde su origen primitivo. En su artículo concluyó que los únicos descendientes de Adán y Eva eran quienes pertenecían a la raza Caucásica y que el Génesis bíblico sólo hacía referencia a la "raza blanca". Fundamentó su propuesta pseudocientífica en la aparente coincidencia de la distribución geográfica de las razas humanas y de los animales, y en la falta de correlación entre las condiciones climáticas y la presencia de razas similares o diferentes. Agassiz consideraba que así como una variedad de peces había sido colocada en océanos diferentes, o peces muy diversos convivían en un mismo mar, las diferentes razas de hombres habían sido colocadas intencionalmente en las partes del mundo que les correspondían (Agassiz, 1850:29).

No es difícil suponer que el naturalista decimonónico creía observar integrantes de las razas "mongólica" y "africana" o "negra", a través de los daguerrotipos de Joseph Zealy y Lorenzo Chase. En los seis daguerrotipos de personas "chinas", Agassiz probablemente miraba a personas de color "amarillo pálido", con "mejillas prominentes" y ojos "muy oblicuos" con angostas fisuras -tal como describió a los chinos en el ensayo que se ha reseñado arriba- (Agassiz, 1850:17). Se trataba, para él, de personas con rostros menos regulares y bellos que los de los malayos. Consideraba que los chinos eran engañosos, astutos y cobardes, como el resto de los mongoles, pero les reconocía como una "nación" con registros históricos abundantes (p. 35, 3).

Los daguerrotipos de Lorenzo Chase muestran a personas chinas con indumentaria que parece compartir su origen, además de sombreros, aretes y peinados sofisticados, desde trenzas -en el caso de los hombres-, hasta diversas elevaciones de cabello con moños, prendedores y otros aditamentos que parecen incluir joyas y flores, en el caso de las mujeres. Resulta 
consistente con la posición que ocupan en la jerarquía racial de Agassiz, el hecho de que se encuentren sentados sobre una silla elegante de madera, con cojines adornados. La mirada de los hombres y las mujeres chinas en los seis daguerrotipos expresan cierta seguridad; los ojos parecen mirar fijamente hacia el frente, ya sea hacia la cámara o hacia alguna pared, cuando aparecen de perfil.

En 1868 Agassiz indicó que las posiciones habituales para las fotografías de Historia Natural que permitieran comparar individuos o especímenes eran: "frente completo, perfil perfecto y por atrás” (Agassiz, 1868: 529). En 1850, Chase eligió mostrar a las personas chinas e hindúes en posición corporal de tres cuartos, mientras que los hombres nativo-americanos aparecen de frente. En cambio, los daguerrotipos de Zealy retratan a personas negras esclavizadas en frente, perfil y por atrás, es decir, precisamente en las posiciones que Agassiz señaló como habituales. Estas diferencias en la representación corporal pueden relacionarse con la posición que ocupaban respectivamente en la jerarquía racial.

Los daguerrotipos de personas esclavizadas que Joseph Zealy hizo para Agassiz, por intermediación de Robert Gibbes, guardan otras diferencias con aquellos de personas "chinas". Uno de los aspectos más contrastantes es la falta de ropa, pues en cinco de ellos las personas aparecen completamente desnudas y en los restantes diez, sólo parecen estar cubiertos de la cintura para abajo - parte del cuerpo que prácticamente no se muestra en los daguerrotipos-. La desnudez se relaciona con el interés antropométrico del periodo y es congruente con la posición en que el naturalista les clasificaba dentro de su escala racial. Esta forma de representación coincide con la tradición de medir los cuerpos de algunos seres humanos en particular y también puede considerarse parte de la práctica racista de fetichizar a ciertos seres humanos, reducirlos a un objeto, erotizarles, negarles parte de su condición humana (Hall, 2010: 437-439). Como denunció Fanon: "el negro no es más que pura biología. Los negros son unas bestias. Viven desnudos" (1968: 210). Estos daguerrotipos alimentan esta representación y al mismo tiempo son producto de ella.

Otra diferencia notable es la ausencia de sombreros, así como el corto tamaño del cabello, especialmente en el caso de las mujeres. Mientras las "chinas" ostentan peinados sofisticados, las "negras" apenas si tienen pelo alrededor de la cabeza, lo que conduce a preguntarnos si se trataba de la forma que acostumbraban o si su cabello fue cercenado a propósito del daguerrotipo. Y si fue recortado, ¿acaso fue para observar mejor la forma del cráneo?

El investigador Brian Wallis (1995:44-45) explicó que Robert Gibbes había presentado sus trabajos en Charleston, conocía a Morton y a Agassiz, y era "hijo de una prominente familia de Carolina del Sur, amigo cercano de muchos dueños eminentes de plantaciones". En un Censo de 1850 realizado en Richland, un hombre con el mismo nombre se registró como dueño de 18 esclavos (9 hombres y 9 mujeres); el mayor tenía 65 años y el menor, 2 (United States Census, 1850:29, disponible en: familysearch.org). En ese mismo año, Gibbes dio un recorrido a Agassiz por las plantaciones para que examinara a personas de origen Ebo, Fula, Gullah, Guinea, Coromante, Mandingo y Congo, y seleccionara a algunos para ser retratados por Zealy (Wallis, 1995:46).

Estos no eran los primeros daguerrotipos que se obtenían para analizar "tipos raciales" y reafirmar teorías pseudocientí- ficas sobre las razas. De acuerdo a Juan Naranjo (2006:12), en 1842 el naturalista Berthelot realizó fotografías con fines similares en las islas Canarias, mientras que Tiesson obtuvo daguerrotipos de "indios botocudos" de Brasil para que Étienne Serres los incluyera en sus investigaciones de antropología comparada. Agassiz se insertaría en esta tradición que vincula a la fotografía con la ciencia o, mejor dicho, con el conocimiento asociado al racismo y al colonialismo que impregnaban las ciencias del periodo. En 1868 el propio Agassiz (1868:529) afirmó que los "retratos" fotográficos eran parte del método de historia natural del cual partía para "comparar especímenes de diferentes especies". La creación de museos y la circulación de este tipo de fotografías también fueron de utilidad para las pesquisas de antropólogos del momento, impactando en el desarrollo de la Antropología (Naranjo, 2006).

Cuatro años antes de que Agassiz recibiera los daguerrotipos de personas esclavizadas, había tenido su primer encuentro con quienes -según él- conformaban una "raza degradada y degenerada" (Carta de Agassiz a su madre, 1846, en Gould, 2011:90). En la carta para su madre, describió la mirada que tenía hacia estas personas:

...al ver sus negros rostros, con esos labios gruesos y la mueca de sus dentudas bocas, la lana de su cabeza, las piernas torcidas, las manos alargadas, sus grandes uñas arqueadas y, sobre todo, el color lívido de la palma de sus manos, no pude dejar de clavar mis ojos en su rostro para indicarles que se mantuvieran bien lejos. Y cuando esa horrible mano se dirigía hacia mi plato para servirme, deseé ser capaz de marcharme a comer un trozo de pan en cualquier otro sitio con tal de no cenar atendido por esos camareros (p. 90).

Con base en este escrito, es posible suponer que cuando el naturalista suizo sostuvo los daguerrotipos de estas personas prestó especial atención a sus labios y su cabello. En la mayoría de ellos, no pudo ver las manos y piernas, pues el cuerpo entero solo aparece en cinco de estos daguerrotipos, en los cuales se muestra a Jem -de frente, de perfil y en visión trasera- y a Alfred -de perfil y en visión trasera-. En cambio, en diez de los daguerrotipos, los cuerpos se muestran hasta la cintura.

Agassiz pudo examinar los senos de Delia y Drana, de frente y de perfil; algunos años después, su minuciosa observación sobre el cuerpo femenino le permitió comparar los pechos de las "indias" y las "negras", en su texto Permanence of characteristics in different species: "las mujeres indias tienen un pecho cónico, firme y con buen soporte... el pezón se proyecta sobre el brazo en una vista completa del torso. En las negras el pecho es más cilíndrico, más suelto, y más flácido, el pezón está volteado hacia adelante y hacia abajo, de modo que en una vista de frente se proyecta sobre el torso" (Agassiz, 1868: 532). La representación desnuda o semidesnuda que solicitó de estas mujeres, es una forma de reduccionismo que coincide con la interpretación que hace Stuart Hall (2010:437-439) al analizar los actos que se hicieron a Sarah Baartman, en vida y tras su muerte: "fue sometida a una forma de reduccionismo - una estrategia frecuentemente aplicada a la representación de los cuerpos de las mujeres, de cualquier raza, especialmente en la pornografía-". En el caso de Agassiz, es necesario recordar que también eligió representar a hombres despojados de vestimenta. 
En 1850, Agassiz consideraba que en toda África las personas eran predominantemente negros a pesar de las diferencias que podía haber entre personas de "Senegal”, “Mozambique", "Congo" o "Guinea”. De hecho, reconoció haber dedicado especial atención a dicha materia, examinando cercanamente a muchos nativos africanos que pertenecían a diferentes "tribus" e incluso presumía tener la capacidad de distinguir la "nación" a la que pertenecían, sin que le informaran al respecto e incluso cuando querían engañarlo. Esta habilidad en Agassiz resulta sorprendente -especialmente porque "Guinea", "Senegal" y "Mozambique" son zonas o regiones de África y no grupos étnicos ("tribus" o "naciones")-. Este incidente conduce a preguntarnos sobre la precisión de las referencias escritas sobre los papeles que acompañan a varios de estos daguerrotipos donde se indica el origen de las personas de origen africano. Por ejemplo, Jack, de quien se dice que era chofer, fue registrado con la palabra "Guinea"; ¿se tratará del origen que él mismo reportó a Robert Gibbes o a Joseph Zealy? ¿O habrá sido Agassiz quien adivinó su procedencia?

Para Agassiz (1850:35), los negros eran sumisos, serviles e imitativos; se trataba de una raza con una "peculiar apatía, una peculiar indiferencia a las ventajas de la sociedad civilizada". En 1852 escribió una carta a la Sra. Holbrook, quien aparentemente no compartía sus conclusiones sobre la humanidad. Louis Agassiz le explicó que las razas de monos se clasificaban a partir de detalles como la forma de su nariz, sus mejillas y labios o la posición de los ojos; “La verdad es-dijo-, que las diferentes especies admitidas por algunos entre los simios son en realidad razas de monos, 0 , las razas entre los hombres no son más que lo que se llama especies entre los monos" (1885:501). En 1863 amplió los adjetivos hacia estas personas en la carta que mantuvo con Howe; informó que los negros eran indolentes, juguetones, sensuales, imitativos, subordinados, de buena naturaleza, versátiles, inestables en su propósito, devotos y cariñosos, envueltos en la barbarie (Agassiz, 1885:605-606).

Agassiz nutrió las bases del racismo pseudocientífico con argumentos que fueron reconocidos en su momento debido a la autoridad que tuvo en el siglo XIX. De acuerdo a Wieviorka (2009:13) el racismo caracteriza a "un conjunto humano mediante atributos naturales, asociados a su vez a características intelectuales y morales aplicables a cada individuo relacionado con este conjunto" y, a partir de ello, adopta "prácticas de inferiorización y exclusión". Por tanto, no sólo se trata de un fenómeno ideológico, político o doctrinario, sino que también implica un conjunto de prácticas y conductas entre personas y grupos humanos que terminan por tomar la forma de prejuicios, estereotipos, segregación, exclusión y discriminación (p. 51-52).

Este naturalista no se limitó a afirmar y explicar las supuestas diferencias entre las razas humanas, sino que insistió en que el conocimiento de dichas diferencias imposibilitaba un trato igualitario. Para él, "los atributos superiores que caracterizan al hombre en su desarrollo superior se presentan en las razas en proporciones muy diferentes" (Agassiz, 1850:35); por ello, no tenía la menor duda de que las "razas inferiores" o "razas de color”, serían conducidas de manera más juiciosa si se guiaran por una conciencia absoluta sobre la verdadera diferencia entre "nosotros" y "ellos", así como por el deseo de fomentar las disposiciones más marcadas de cada raza, "en lugar de tratarlos en términos de igualdad" (p. 36). El naturalista suizo no sólo pretendía estudiar dichas particularidades, sino también hacer lo que estuviese en sus manos para desarrollar a las razas inferiores. Consideraba que era una falsa filantropía y una filosofía de simulación el asumir que las razas tenían las mis- mas habilidades, poderes y disposiciones naturales, y que en consecuencia debían tener la misma posición en la sociedad humana (p. 34).

El racismo ayudó a justificar crímenes graves contra la humanidad y muchas de sus consecuencias siguen vigentes. Considero que uno de los compromisos de los historiadores y antropólogos es dar cuenta de dichas prácticas y procesos. Tenemos el reto de colaborar a resignificar a aquellos seres humanos que fueron víctimas directas de la esclavitud y del racismo, pero que además construyeron las sociedades de las cuales fueron parte mediante sus aportes económicos, sociales, culturales y políticos. Por ello, el siguiente apartado presenta aspectos mínimos de las personas de origen africano y asiático que aparecen en los daguerrotipos, centrándome en dos mujeres. 


\section{LUM-AKUM Y DRANA. LA MIRADA ANTROPOLÓGICA DE LA} FUENTE HISTÓRICA

En 1868 Louis Agassiz llamó “retratos" a las fotografías de personas indígenas y de origen africano que había obtenido en varias partes de Brasil y que utilizaría en sus investigaciones de Historia Natural. Allan Sekula (1986:6-7) aclara las diferencias entre los "retratos fotográficos" y los "retratos pictóricos"; mientras que estos últimos aseguraron una presentación del yo burgués, la fotografía tuvo un papel diferente derivado de las necesidades médicas y anatómicas; ayudó a establecer los límites con respecto al "Otro" y a definir una visión generalizada o una tipología de la desviación y la patología social.

Para Brian Wallis (1995:55-59) los daguerrotipos de personas esclavizadas de Agassiz son fotografías "tipos" más que "retratos", considerando su contexto de producción y sus principales usos en el periodo; afirmó que se trata de "una forma de colonialismo representacional". Coincido con su análisis sobre el tipo de objeto/imagen al que nos enfrentamos, no obstante, resulta fundamental re-interpretar estos daguerrotipos en tanto fuentes históricas para reconocer a los seres humanos que aparecen en ellos. Como explicó Peter Burke (2005:236): “quien desee utilizar las imágenes como testimonios deberá estar consciente en todo momento... que la mayoría de ellas no fueron producidas con esa finalidad".

Lum-Akum, una mujer que es descrita como "china", se presenta de perfil en un daguerrotipo de 1850. Otras personas del mismo origen fueron retratadas en ese año por Lorenzo Chase, como Aleet-Mong, Soo-Chune y Pwan Ye-Koo. En la descripción del Museo Peabody sólo se indica que se trata de la vista de perfil de una "mujer china" de nombre "Lum-Akum". En el caso de los hombres, Aleet-Mong y Soo-Chune aparecen otros nombres entre paréntesis: “T'sow-Chaoong” y "Le-Kaw-Hing”, respectivamente.

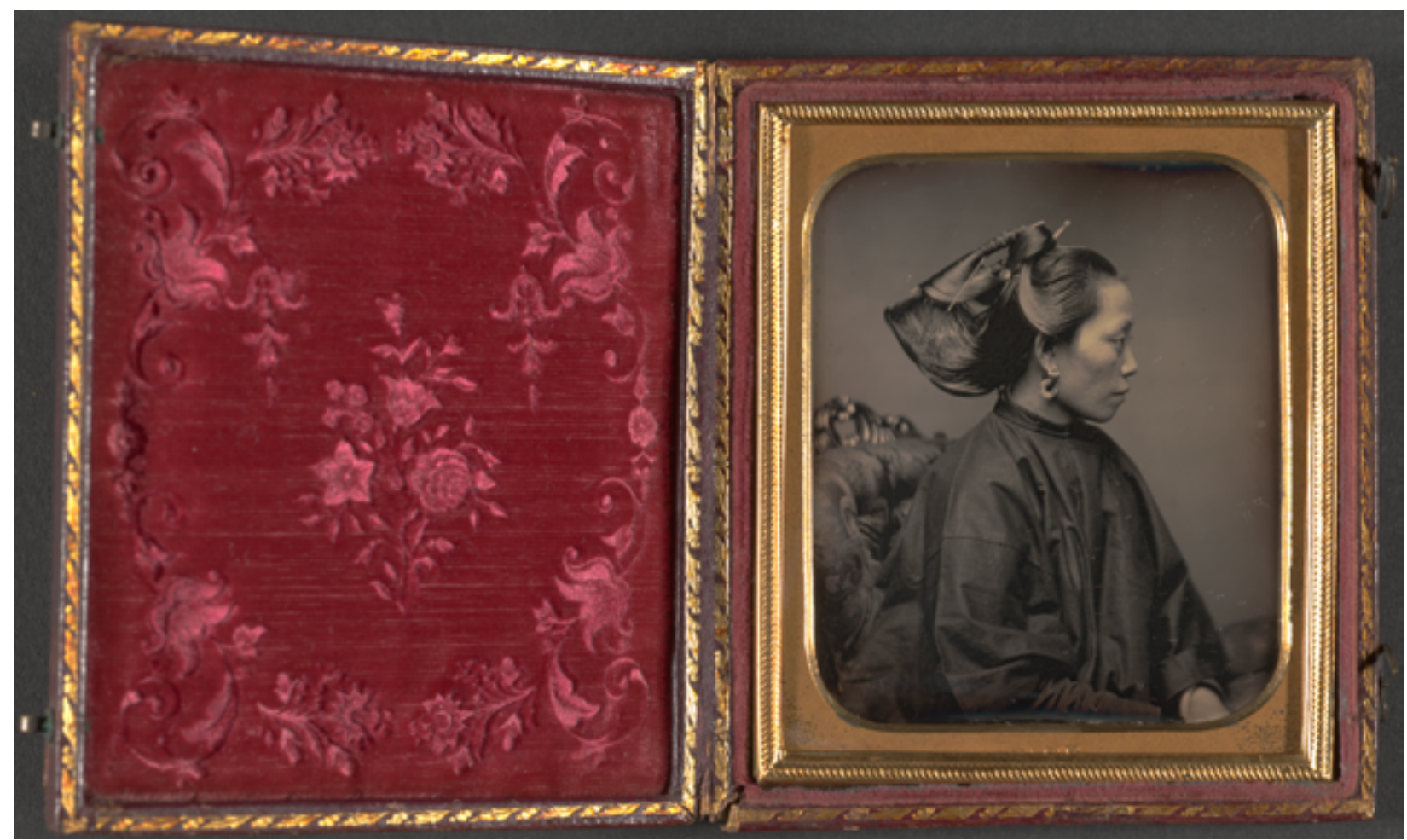

Imagen 1. Lum-Akum. Daguerrotipo de Lorenzo Chase, $1850 .^{3}$

Fuente: Courtesy of the Peabody Museum of Archaeology and Ethnology, Harvard University, PM35-5-10/53056. Véase tabla 1, núm. 6.
En 1850, el hombre de espectáculo y el circo Phineas Taylor Barnum, consiguió mejorar el entretenimiento que comercializaba incluyendo música traída directamente de China, que se presentaría en el Museo Chino de Barnum. Las cuatro personas que aparecen en los daguerrotipos de Lorenzo Chase que Louis Agassiz coleccionó, son precisamente integrantes de este grupo musical: The Chinese Family, “La Familia China”. Un anuncio que al parecer fue promocionado en periódicos del momento les anunciaba como parte de las funciones del afamado Barnum; y parecen haber sido éxito pues afirmó que en seis días había convocado a veinte mil personas (Kuo Wei Tchen, 2001:118).

La atracción principal del espectáculo era Pwan Ye-Koo, de 17 años, a causa de su "belleza”, su "gracia” y sus pies atados que se decía que eran de apenas 2.5 pulgadas de largo (Kuo Wei Tchen, 2001:118). En cambio, Lum-Akum, de 23 años, era su "sirvienta". El maestro de música era Soo-Chune, cuyo nombre original era Le-Kaw-Hing, de 32 años. Participaban también sus dos hijos, Amoon y Mun Chune, de 7 y 3 años, respectivamente. Aleet-Mong, de 18 años, era un intérprete y su nombre 
-T'sow-Chaoong- también había sido modificado para satisfacer los caprichos de P. T. Barnum (Moon, 2005:63).

Aunque Lum Akum no llegó a Estados Unidos de manera forzada ni fue esclavizada, su condición de "sirvienta" de Pwan Ye-Koo le colocaría en una situación de desventaja. Además, el hecho de que Barnum modificara los nombres de dos de los in tegrantes de The Chinese Family nos permite suponer que todos los integrantes de este grupo -y de los cuales solo Amoon, Mun Chune y Le-Kaw-Hing o Soo-Chune parecen haber tenido un vínculo familiar- estaban a expensas del hombre de espectáculo. La exhibición de personas en circos se relaciona con los zoológicos humanos, aprobados en el siglo XVIII por el conde de Buffon -otro naturalista-, aunque se desarrollaron en Europa en el último tercio del siglo XIX, manteniéndose por lo menos hasta mediados del siglo XX (Báez y Mason, 2006).

En cambio, Drana fue una mujer de origen africano nacida en Estados Unidos, esclavizada en una plantación de Carolina del Sur. En la descripción del Museo Peabody sobre los dague- rrotipos donde aparece Drana, se indica que es una mujer negra madura, fotografiada de frente y de perfil, respectivamente, desnuda hasta la cintura y con la ropa acumulada a esa altura lo que lleva a pensar que fue despojada de parte de su vestimenta para obtener el daguerrotipo. No se observa ningún patrón en su ropa, sólo se reconoce el color blanco de la tela, probablemente algodón. En el caso de otra mujer afrodescendiente, Delia, se observan líneas oscuras que forman un patrón sobre el color claro de la tela. El cabello de Drana cubre su cabeza y aparece corto, a excepción de un pequeño mechón de un lado de su frente que sólo se distingue en la posición de perfil.

Un papel que acompaña la fotografía indica su nombre, que nació en el país y que pertenecía a la plantación de Benjamin F. Taylor (Richland, Columbia, Carolina de Sur). También se especifica que es hija de Jack, de Guinea (África Occidental), y gracias a la fotografía de él se sabe que era chofer. Se desconocen las actividades que desempeñaba Drana y éstas no pueden deducirse a partir del daguerrotipo. Tampoco se cuenta con información sobre otros parientes, ni se sabe si tuvo hijos.

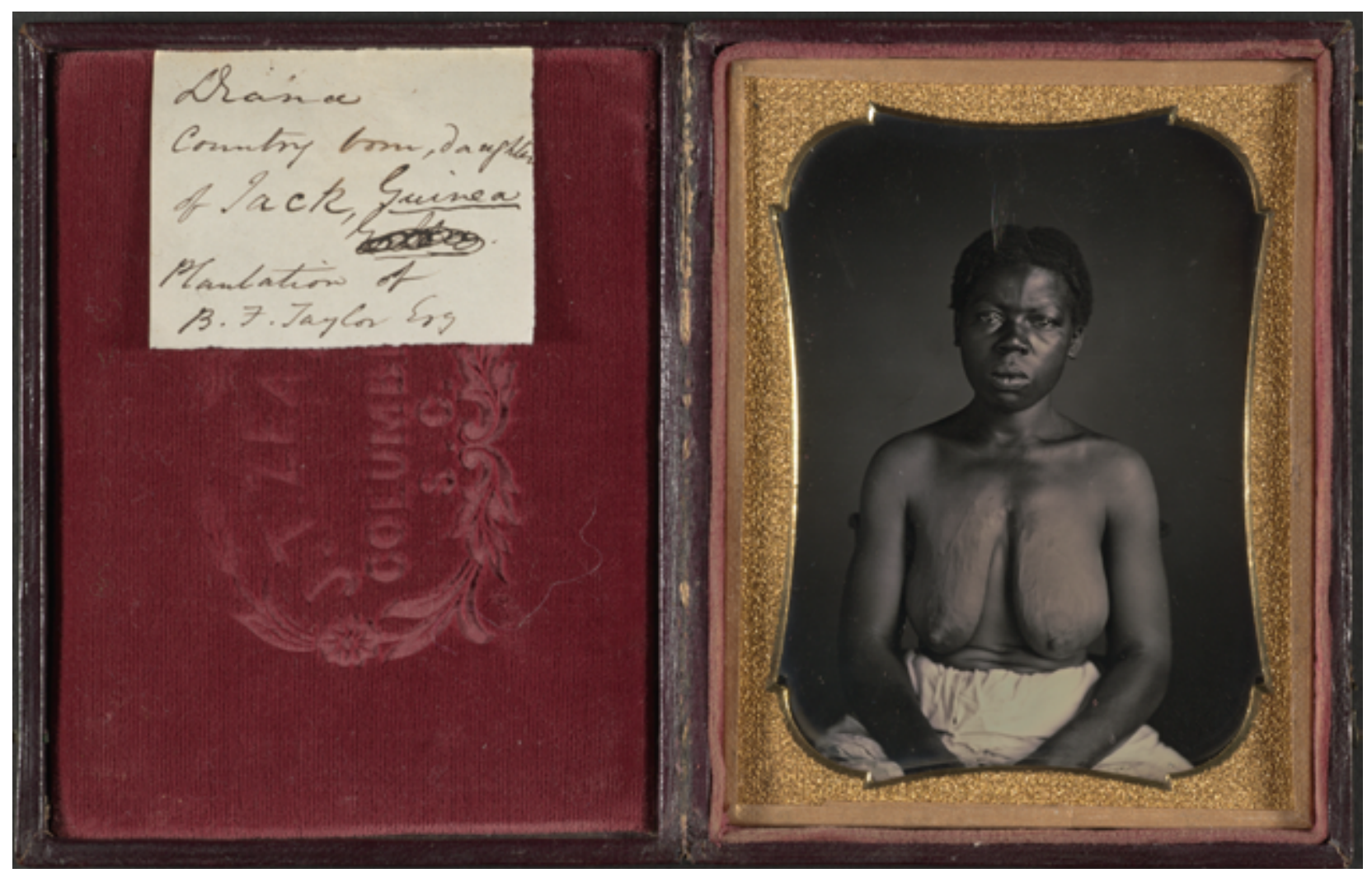

Imagen 2. Drana. Daguerrotipo de J. Zealy. ${ }^{4}$

Fuente: Courtesy of the Peabody Museum of Archaeology and 4 Ethnology, Harvard University, PM35-5-10/53041.
Cuando se observa a Drana de frente, llama la atención las marcas en sus senos, las cuales podrían deberse a algún padecimiento de la piel, a algún castigo o pudieran ser estrías a causa de amamantar, debido a embarazos, cambios de peso o a cierta actividad laboral. Los músculos de sus hombros y sus brazos expresan fuerza física tras años de labor, aunque no se sabe si su trabajo en la plantación era agrícola o doméstico.

En la plantación donde ella vivía, del esclavista Taylor, había 179 personas esclavizadas, de acuerdo al Censo de Richland County, Carolina del Sur (United States Census, Slave Schedule, 1850, fs. 91-93). A partir de otros daguerrotipos de Zealy sabemos que en la misma plantación residían Jack (padre de Drana); Delia y su padre, Renty, de Congo. A partir del censo de 1850 se encontró que todos eran considerados negros, excepto tres mulatos, y que la mayoría eran varones (hombres: 108, 60.3\%; mujeres: $71,39.7 \%$ ). 


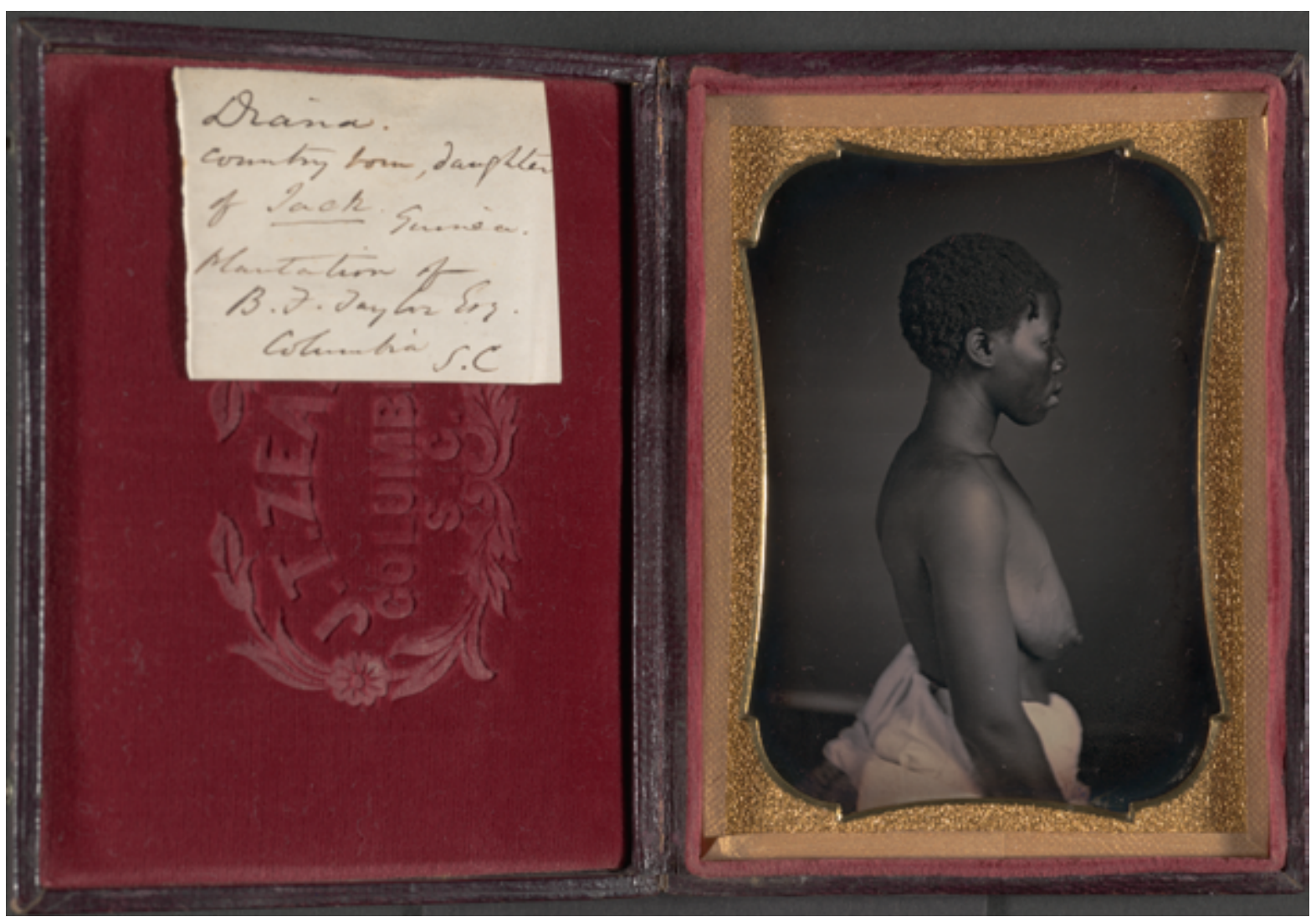

Las edades de las personas esclavizadas oscilaron entre los 7 meses y los 70 años; pero había una proporción alta de niños, ya que $39.1 \%$ de ellos tenían 14 años o menos. En cambio, se observa un descenso en la cantidad de personas mayores de 40 , lo que pudiera revelar una alta mortandad a edades tempranas, aunque también es posible que hayan sido enviados a otros espacios o que hayan escapado. El pequeño aumento en la cantidad de personas entre 30 y 39 años pudiera relacionarse con la compra de hombres y mujeres de esta edad. Por su parte, la cantidad de niños menores de 10 años y la diferencia con respecto a aquellos de entre 10 y 19 años, pudiera deberse a la venta de niños.

\begin{tabular}{|c|c|c|}
\hline Edad (años) & Cantidad & Porcentaje \\
\hline o a 9 & 51 & $28,5 \%$ \\
\hline 10 a 19 & 33 & $18,4 \%$ \\
\hline 20 a 29 & 23 & $12,8 \%$ \\
\hline 30 a 39 & 24 & $13,4 \%$ \\
\hline 40 a 49 & 18 & $10,1 \%$ \\
\hline 50 a 59 & 13 & $7,3 \%$ \\
\hline 60 a 69 & 16 & $8,9 \%$ \\
\hline 70 a 79 & 1 & $0,6 \%$ \\
\hline Total & 179 & $100,0 \%$ \\
\hline
\end{tabular}

Tabla 3. Edades de personas esclavizadas (Plantación donde trabajaba Drana) ${ }^{5}$
Imagen 3. Drana. Daguerrotipo de J. Zealy. ${ }^{6}$

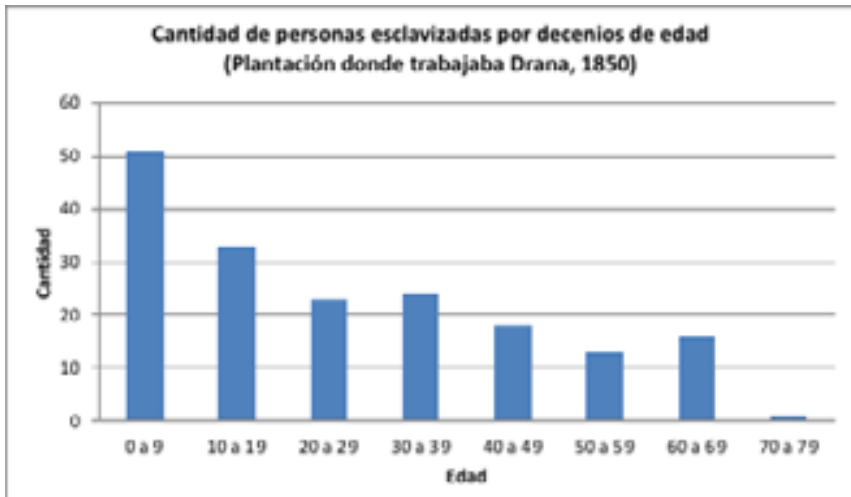

Gráfica 1. ${ }^{7}$

6 Fuente: Courtesy of the Peabody Museum of Archaeology and Ethnology, Harvard University, PM35-5-10/53042

Fuente: Elaboración propia a partir de "United States Census (Slave Schedule)”, Carolina del Sur, Columbia, Richland county, 1850, fojas 91-93. 


\section{CONSIDERACIONES FINALES}

A partir de dos miradas contrastantes - la mirada racista y la mirada etnohistórica/antropológica- se ha mostrado cómo el racismo norteamericano del siglo XIX se relacionó con el progreso de tecnologías como la fotografía y el desarrollo de las ciencias del periodo. Los daguerrotipos de personas de origen africano y asiático que coleccionó Louis Agassiz, uno de los naturalistas dedicados a examinar seres humanos y reducirlos a especímenes clasificables en diferentes razas, son muestra de ello. Como se señaló, el racismo no sólo es una doctrina, sino que también implica prácticas de inferiorización, exclusión y explotación, como son la esclavización y la exhibición de seres humanos en museos, circos o zoológicos. El espectáculo de mostrar a personas chinas como curiosidades de Oriente, contribuyó a la construcción de una mirada orientalista, es decir: "la percepción estereotipada de una cultura por otra, o de los individuos de una cultura por los individuos de otra" (Burke, 2005:165; cfr. Said, 2008).

En el siglo XIX los chinos eran considerados parte de la raza amarilla, "inferior" a la Caucásica; de acuerdo a Michael Keevak (2011), es precisamente en ese contexto cuando se relaciona la Trisomía 21 o Síndrome de Down con el origen mongólico. Al mismo tiempo, las personas de origen africano fueron constantemente comparadas con animales que se consideraban muy inferiores en inteligencia al ser humano; fueron representadas cerca de la barbarie, en el nivel más bajo de la escala racial. El desarrollo de este tipo de ideas y prácticas -en nombre de la ciencia y en defensa de los privilegios de los propios científicos- no hace más que confirmar la inhumanidad de los sistemas que oprimieron a seres humanos de todas las edades.

De acuerdo con Wallis (1995 ;40-41), en el siglo XIX hubo dos tipos de tradiciones que impregnaron el museo moderno norteamericano: los esquemas de organización de Agassiz y la teatralidad de P. T. Barnum. Así, no sorprende que Barnum se encargara de incluir a Lum-Akum y otros chinos en su circo, mientras Agassiz coleccionaba y examinaba sus retratos junto a aquellos de personas de origen africano, como Drana.

A partir de la comparación de daguerrotipos de personas de origen asiático y africano, este trabajo contribuye al reconocimiento de la relación entre un fenómeno tan perjudicial como el racismo y la producción de imágenes asociadas al desarrollo de las ciencias decimonónicas. Además, busca visibilizar la importancia de las mujeres y los hombres de origen africano y asiático que construyeron las sociedades de las cuales fueron parte, a pesar de enfrentar condiciones de inferiorización, esclavitud, explotación y exhibicionismo, prácticas características del racismo del periodo. Finalmente, espera coadyuvar a la recuperación de las experiencias de Drana y Lum-Akum para honrar su memoria. 
Agassiz, E. C. (ed.) (1885). Louis Agassiz. His life and Correspondence. Boston y Nueva York: The University of Cambridge.

Agassiz, L. (1850). The diversity of origin of the human races. Christian Examiner (julio). Maryland: National Library of Medicine, 1-36.

Agassiz, L. (1868). Permanence of Characteristics in different human species. En: Agassiz, L.; Agassiz E., A Journey in Brazil. Boston: Ticknor and Fields, 529-532.

Báez, C. y P. Mason (2006). Zoológicos humanos. Fotografías de fueguinos y mapuche en le Jardin d'Acclimatation de Paris, siglo XIX. Santiago: Pehuén.

Burke, P. (2005). Visto y no visto. El uso de la imagen como documento histórico. Barcelona: Crítica.

Fanon, F. (1968). Piel negra. Máscaras blancas. La Habana: Instituto del Libro.

Geulen, C. (2010). Breve historia del racismo. Madrid: Alianza.

Gould, J. (2011). La falsa medida del hombre. Barcelona: Crítica.

Hall, S. (Restrepo, E.; Walsh, C.; Vich, V. eds.) (2010). Sin garantías. Trayectorias y problemáticas en estudios culturales. Popayán: Universidad Javeriana, Instituto de Estudios Peruanos, Universidad Anfina Simón Bolívar, Envión Editores.

Irmscher, C. (2013). Louis Agassiz, Creator of American Science. Boston: Houghton Mifflin Harcourt.

Keevak, M. (2011). Becoming Yellow. A Short History of Racial Thinking. Princeton: Princeton University.

Kuo Wei Tchen, J. (2001). New York before Chinatown. Orientalism and the Shaping of American Culture 1776-1882. Baltimore: John Hopkins University.

Lurie, E. (1954). Louis Agassiz and the Races of Man. Isis 45(3), The University of Chicago Press, 227-242.

Machado, M. (2012). Ninteenth-Century Scientific Travel and Racial Photography: The Formation of Louis Agassiz's Brazilian Collection, Mirror of Race, disponible en: http:// mirrorofrace.org/machado

Mintz, S. y R. Price (2012). El origen de la cultura africano-americana. Una perspectiva antropológica. México: CIESAS.

Moon, K. (2005). Yellowface. Creating the Chinese in American Popular Music and Performance, 1850-1920. Nueva Jersey: Rutgers University Press.

Morton, S. (1844). An inquiry into the distinctive characteristics of the aboriginal race of America. Filadefia: John Penington, Chestnut Street.

Morton, S. (1839). Crania Americana; or A Comparative view of the skulls of various aboriginal nations of North and South America. Filadelfia: Simpkin, Marshal y Co.

Morton, S. (1849). Observations on the size of the brain in various races and families of man. Proceedings of the Academy of Natural Sciences (octubre). Maryland: National Library of Medicine.

Morton, S. (1844). Crania Aegyptiaca; or Observations on Egyptian Ethnography, derived from Anatomy, history and the Monuments. Filadelfia: John Penington.

Murray, Y. (2012-2013). From Here I Saw What Happened and I Cried: Carrie Mae Weems' Challenge to the Harvard Archive. Unbound: Harvard Journal of the Legal Left 1 8(1), 1-78.

Naranjo, J. (2006). Fotografía, antropología y colonialismo (1845-2006). Barcelona: Gustavo Gili.

Palmquist, P. y T. Kailbourn (2000), Pioneer Photographers of the Far West. A Biographical Dictionary, 1840-1865. California: Stanford University.

Rogers, M. (2012). Louis Agassiz: Full Face and Profile, Mirror of Race, disponible en: mirrorofrace.org/louis-agassiz-full-face-and-profile/\#1.

Rogers, M. (2010). Delia's Tears: Race, Science and Photography in Nineteenth-Century America. Connecticut: Yale University Press.

Said, E. (2008). Orientalismo. Barcelona: De Bolsillo.

Sekula, A. (1986). The body and the archive. October 39(invierno), 1986, 3-64. 
South African History Online (2013) en: www.sahistory.org.za/people/sara-saartjie-baartman, actualizado en febrero de 2016.

Tagg, J. (1998). El peso de la representación. Ensayos sobre fotografías e historias. México:Gustavo Gili.

Wallis, B. (1995). Black Bodies, White Science: Louis Agassiz's Salve Daguerrotypes, American Art 9(2), 38-61.

Wieviorka, M. (2009). El racismo: una introducción. Barcelona: Gedisa.

\section{FUENTES DOCUMENTALES Y FOTOGRÁFICAS}

“United States Census (Slave Schedule)", Carolina del Sur, Columbia, Richland, 1850, disponible en: familysearch.org.

“United States Census (Slave Schedule)", Carolina del Sur, Columbia, Richland County, 1850, disponible en: familysearch.org.

Chase, Lorenzo, Suffolk, Massachusetts, Boston, 1850, en el Museo Peabody de Arqueología y Etnología, Universidad de Harvard, EUA, disponibles en: pmem.unix.fas. harvard.edu:8080/peabody. Daguerrotipos.

Zealy, Joseph Thomas, Richland, Columbia, Carolina del Sur, 1850, en el Museo Peabody de Arqueología y Etnología, Universidad de Harvard, EUA, disponibles en: pmem. unix.fas.harvard.edu:8080/peabody. Daguerrotipos.

\section{AGRADECIMIENTOS ESPECIALES}

A, Dr. Álvaro Rodriguez Luévano. 